\title{
ESTÁGIO ATUAL DA LEISHMANIOSE CUTÂNEA DIFUSA (LCD) NO ESTADO DO MARANHÃO. I. RELATO PRELIMINAR
}

\author{
Jackson M.L. Costa, Ana Cristina R. Saldanha, Conceição de Maria P. e Silva, \\ Artur Serra Neto, Clóvis Eduardo S. Galvão, Angélica M.R. Godinho, \\ Antônio Rafael da Silva, Wellington Silva Mendes e Ana Carla Mello e Silva.
}

Um dado concreto sobre a existência da leishmaniose tegumentar americana no Estado do Maranhão é a referência de Terra ${ }^{11}$ em 1913, que diz ter encontrado leishmanias em lesões ulceradas de pacientes procedentes de todos os estados da federação, destacando o Rio de Janeiro, Minas Gerais, Mato Grosso, Espírito Santo, Alagoas, Paraíba, Maranhão, Pernambuco, Amazonas e Acre, como os de maiores problemas em relação a esta doença.

Em artigo sobre leishmaniose em Minas Gerais, Orsini ${ }^{7} 1940$, aventa que provavelmente a referida doença tenha chegado até o seu estado, devido os trabalhadores do Norte do Brasil (Maranhão, Piaú, Ceará, Bahia) que emigraram para o Sul através do Sertão e da Zona da Mata, levando possivelmente a doença até esta região.

No que diz respeito à Leishmaniose Cutânea Difusa (LCD), referente ao nosso estado, o primeiro relato data de 1960 , quando Porto Marques 8 descreve um caso enviado pelo professor Cloves Chaves que pertencia à disciplina de Dermatologia da Faculdade de Medicina da UFMA, caso este referido por Nery Guimaraes $^{5} 6$ em 1965, como o sétimo da literatura nacional.
Em 1963, Nery Guimaraes relata, na Academia Nacional de Medicina, o encontro de um paciente proveniente do Maranhão (localidade de Riachão), que se encontrava doente há 2 anos, com nódulos queloidiformes na perna esquerda, extremamente ri$\cos$ em leishmania e reação de Montenegro negativa.

Em 1975, a disciplina de Dermatologia da UFMA destaca um novo caso de LCD; tratava-se de um jovem proveniente do Município de Rosário-MA, portador de lesões nodulares disseminadas pelo corpo, levando o paciente a freqüentes crises depressivas, culminando com a morte do mesmo após sua transferência para o Hospital Universitário Gaffrée Cuinle no Estado do Rio de Janeiro.

Silva e cols 910 , em 1979, estudaram um surto epidêmico de leishmaniose tegumentar americana na Colonização Agricola de Buriticupu, Município de Santa Luzia-MA, chamando a atenção para o caso de uma criança de 7 anos portadora de forma anérgica da doença.

Com o aparecimento de novos casos de LCD no estado e sentindo a necessidade de respostas para diversas interrogações sobre a evolução da doença, decidimos realizar um estudo retrospectivo e prospec-

Tabela 1 -Algumas caracteristicas clinicas dos pacientes atualmente estudados que apresentam Leishmaniose Cutânea Difusa no Maranhão.

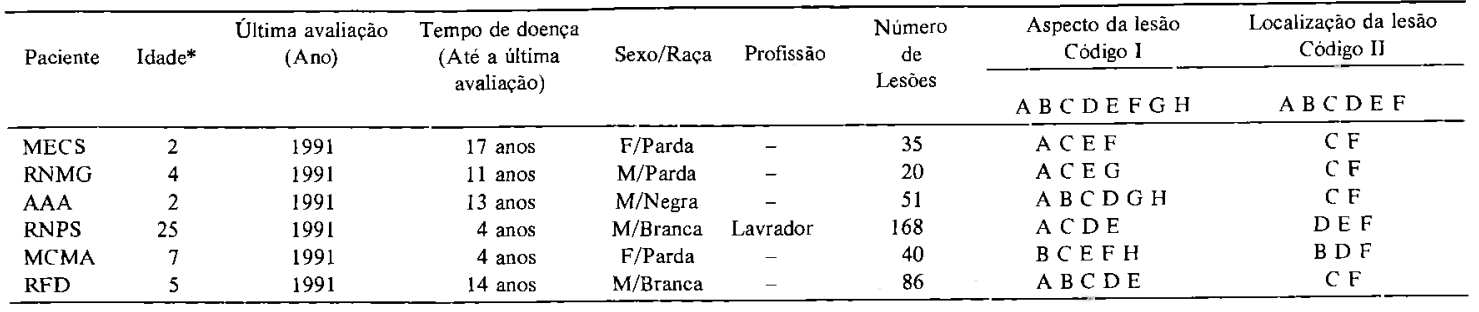

* Inicio da doença.

Chave localização: (Código I): A - Nódulo

$$
\begin{aligned}
& \text { B - Ulcero-vegetante } \\
& \text { C - Ulceração } \\
& \text { D - Tuberculo } \\
& \text { E - Ulcero-crostosa } \\
& \text { F - Mancha hipercrômica } \\
& \text { G - Placas infiltradas } \\
& \text { H - Infiltraçāo da mucosa nasal }
\end{aligned}
$$

(Codigo II): A - MMSS (membros superiores)

B - MMII (membros inferiores)

C - MMSS e MMII (membros superiores e membros inferiores)

D - MMSS e Torax (membros superiores e tórax)

E - MMII e Abdómem

F- Face

Disciplina de Doenças Infecciosas e Parasitárias, Departamento de Patologia, Faculdade de Medicina da Universidade Federal do Maranhão e Hospital dos Servidores do 
tivo da mesma a partir da década de 70 , quando levantamos uma casuística de 6 casos oriundos de diferentes localidades do estado. Chamou-nos a atenção o início da doença, que correspondeu a $83,3 \%$ até os 7 anos de idade, a cronicidade da mesma, pois estamos acompanhando pacientes com 17 anos de evolução da doença e a refratariedade aos tratamentos instituidos. Alguns detalhes sobre os pacientes encontram-se na Tabela 1.

Sobre a LCD, além de sua incurabilidade 124 , eventos epidemiológicos como o momento da infeccão, envolvimento de vários componentes de uma mesma família na doença ${ }^{3}$ e o desenvolvimento de anergia pelo sistema fagocítico mononuclear em presença da Leishmania (Leishmania) amazonensis, responsável pela doença em nosso País, são questốes que necessitam de esclarecimentos urgentes 510

Com os dados preliminares ora apresentados, pretendemos dar conhecimento e chamar a atenção para a importante e controvertida doença no Estado do Maranhão, que inexplicavelmente tem na literatura mundial aproximadamente 150 casos relatados.

\section{REFERÊNCIAS BIBLIOGRÁFICAS}

1. Convit J, Castellanos PF, Ulrich M, Castes M, Rondon A, Pinardi ME, Rodrigues N, Bloom BR, Formica S, Valencillos L, Bretana A. Immunotherapy of cutaneous leishmamiasis. The Journal of Infectious Diseases 160: 104-115, 1989.
2. Convit J, Kerdel-Vegas F. Disseminated cutaneous leishmaniasis. Archives of Dermatology 91: 439-447, 1965.

3. Diaz HB, Martinez D, Quiñones M, Estévez FN. Leishmaniose anérgica na República Dominicana. Estudo de 20 casos. Anais Brasileiros de Dermatologia 60 (supl.): 229-236, 1985.

4. Medina R, Romero J. Estudio sobre la leishmaniasis tegumentaria en Venezuela. Dermatologia Venezuelana 1: 33-36, 1957.

5. Nery-Guimarães FV. Estado atual dos conhecimentos da "forma lepromatoide" da Leishmaniose tegumentar (LT). O Hospital 67: 71-91, 1965.

6. Nery-Guimarães FV. Reprodução em camundongo (Mus musculi) de leishmaniose cutâneo-visceral (Histiocitoma leishmaniótico) ocorrendo na Amazônia. O Hospital 40: 11-24, 1965.

7. Orsini O. Leishmaniose em Minas Gerais. Brasil-Médico Liv: 8-14, 1940.

8. Porto Marques A, Portugal H. Leishmaniose Tegumentar Difusa. O Hospital 57: 11-23, 1960.

9. Silva AR, Martins G, Mello JEM, Araújo JP, Mendes JR e Mendes MG. Surto epidémico de leishmaniose tegumentar americana ocorrido na colonização agrícola de Buriticupu (Estado do Maranhão) Brasil. Revista do Instituto de Medicina Tropical de São Paulo 21 : 43-50, 1979.

10. Silva AR, Mendes JR, Rodrigues MLM, Carvalho ZS, Reis FMP, Melo JEM e Morais JCO. Leishmaniose Cutânea Difusa (LCD). Registro de um caso em Buriticupu(Estado do Maranhão, Brasil). Revista do Instituto de Medicina Tropical de São Paulo 23: 31-35, 1981.

11. Terra F. Leishmaniose Tegumentar no Brasil. Boletim da Sociedade Brasileira de Dermatologia 3: 58-66, 1913. 